\title{
On the Conceptualized Modes of World Engagement of Chinese Kung-fu Films
}

\author{
Zhong Deng \\ School of Foreign Languages \\ Southwest Minzu University \\ Chengdu, China
}

\begin{abstract}
Kung-fu films are among the most heatedly discussed film products originated from China and appraised by the rest of the world. This article intends to go beyond a traditional paradigm of film analys is which is central on characters, plots and the like, so as to render a cognitive exploration of how such films are related to typical Chinese modes of conceptualization of world engagement. We find that Kung-fu films tend to simplify the relations between people and the world, foreground the self-fulfilment of individuals by means of dramatizing the way they overcome worldly obstacles, and advocate a peacefulness-oriented philosophy of Kung-fu in order to reconcile the contradictions between the self and the world. These features are true of many successful Kung-fu films almost without exception, thus indicating the research paradigm employed in this article may serve as a feasible model for further studies.
\end{abstract}

Keywords-Kung-fu films; world engagement; conceptualized modes; research model

\section{INTRODUCTION}

Kung-fu seems to have become a cultural label of China thanks to a huge numbers of Kung-fu novels and Kung-fu films that have been created in the recent decades. Compared with novels, films are more readily accessible in that language barriers are eliminated to a large degree and receptors' imaginations are enormously enhanced by the present-day filmmaking techniques. Despite the world-wide popularity of Kung-fu films as well as Kung-fu stars (Jackie Chen, for example), there remain some perceptions and interpretations that are misleading, inconvenient and problematic, among which are, for instance, Kung-fu films reveal Chinese addiction to violence; Kung-fu films are amusing by nature without any significance beyond entertainment; or Kung-fu films are interesting merely because it is sensational in fighting scenes. We have to admit that such viewpoints have indeed touched upon some features of Kung-fu films, but by no means can we be satisfied with them because they are not able to explain the enduring appeal of Kung-fu films (starting from Bruce Lee in the 1970s) and the endlessly repeated story-line where the hero suffers, struggles and succeeds consecutively. As for the Kungfu feats, even though there have been increasing numbers of new designs, the truth is that many so-called new designs of feats are in fact new names of old designs. Likewise, the presumed pop-corn nature of Kung-fu films also disappoints us because many other types of pop-corn films are losing their momentum of being cheered, but this is not the case for Kung- fu films at all. Therefore, there has arisen a thought-provoking question, a question that needs to be addressed before we may form an improved understanding of what Kung-fu films are of, about and for. More specifically, if we try to discard the abovementioned perceptions, we are obliged to render a better perspective or paradigm so as to enable us to approach the underlying mechanisms of Kung-fu films as much as possible [1]. The following chapters are hence provided to this end.

\section{WORLD ENGAGEMENT}

Our answer to the question above is simple and clear: world engagement. What we mean by this notion is two-fold. Firstly, we aim to describe how the heroes in Kung-fu films have interacted with other individuals, societal and political institutions and moral/ideological obligations. Observations in this manner represent an ontological concern which is central to the exploration of "who I am". Secondly, we intend to figure out how heroes in Kung-fu films have undergone emotional and perceptional transformations in response to their continuous interactions with the world. Such an investigation is philosophically significant as it highlights an epistemological endeavor that outlines the way "how I know the world". Thus, world engagement is not only about self-definition and reorientation, but also about cognition and world-knowingness before it becomes knowledge of the world [2]. Obviously, the consideration of world engagement is essentially different from many previous paradigms as it focuses on more schematized, philosophical and underlying aspects of Kung-fu films and draws heavily upon cognitive science, especially cognitive semantics (because meaning is still the core) and cognitive poetics (because artistic representations are still worth pondering). In other words, we have to be clear-headed that this paradigm is not meant to refute other paradigms, but to fuel the current studies with contributions of cognitive science [3]. For this purposes, two theoretical points have to be made.

To begin with, it is advisable that world engagement is studied from the perspective of conceptualization. Conceptualization is one of the key notions of cognitive semantics, regarded as a mechanism facilitating humans to acquire meaning from the world and symbols (language, music and sculpture, for example) that represent the world [4]. Secondly, world engagement falls into various modes that can be depicted on the basis of directions of movement. Force dynamics, as is termed academically, is a conceptualized depiction and explanation derived from the schematized observation of objects and their movements [5]. Such a 
depiction is applicable to the study of world engagement as well because world engagement is basically concerned with "going into", "staying in" and "going out" and other similar concepts which altogether constitute a continuum. We deem that the proposal of world engagement is the key to a better understanding because it promises the three following achievements.

\section{SIMPLIFICATION OF THE RELATIONS BETWEEN PEOPLE AND THE WORLD}

One of the characteristic artistic approaches applied in many Kung-fu films is that the relations between people and the world are simplified, uniformly structured and schematized to a degree to which they are removed from the central plotting of the story. “Jiang $\mathrm{Hu}$ (江湖)”, for example, as a distinctly Chinese term that appears in almost all Kung-fu films, remains semantically unclear or ambiguous in many stories, somehow alluding to the conjured living space of Kung-fu masters. But this vagueness does not impede the crystallization of the story itself at all as if all the audiences have known what Jiang $\mathrm{Hu}$ is before they try to understand the story. A viable explanation for the defaulted understanding lies justifiably in the simplification of the people-world relations. Unarguably, such simplified relations have their economically and culturally tangible roots in close association with China's agriculture-shaped social settings. Namely, Kung-fu masters are invariably people supported and sustained by the social settings, say, as presents, land lords or whoever that are given fixed roles. Therefore, all the Kongfu-masters, despite their profound knowledge and exceptional feats of martial art, are a well-recognizable group of people who are essentially indistinguishable from each other as defined by a comparatively simple agricultural society. Based upon this socially defined simplicity of people-world relations, Kung-fu novels and films are endowed with a solid foundation on which simplifications of many other aspects of life are made possible, thus "Jiang Hu" becomes grounded in conceptualization. In other words, "Jiang $\mathrm{Hu}$ " is nothing but a simplified projection of a relatively simple social reality. More specifically, in "Jiang Hu", quite many participants are cognitively given a binary value as a conspicuous manifestation of the simplified projection, e.g. benign vs. evil, strong vs. weak, love vs. hate, alive vs. dead, etc.. By making such an arrangement, Kung-fu films succeed, if not become stereotyped, in rendering a cognitively effortless access available the viewers so as to enable them to participate in the story with an assured anticipation that the duel is between the good and the evil, that the evil dooms to failure, that the good has to be subjected to sufferings before winning the final fight, and that all the bad deeds have to be answered for, etc.. Such story lines may not remain as a huge attraction, but they diminish the difficulty in telling and digesting stories, the achievement of which is conceptually in accordance with people's perception of how the world may work in possibly the most simplified ways and of how people may get engaged in the world in ideally most effortless fashions. In this sense, Kung-fu films potentially provide people with a luring implication that the most rewarding pattern of life lies in the simplicity of people-world engagement, in that all the good is surely to defeat all the evil, all the weak is surely to become strong, and the justice is surely to overthrow the injustice, provided that people never give up whatever goals or dreams morally justifiable. This conceptual line is abundantly soaked up in typical Chinese philosophies such Buddhism and Taoism, in which the merits of life are also conceptually binary [6]. Namely, in the former, Yin and Yang invariably indicate and manipulate everything, and in the latter, Shan (the good or benign) punishes $\mathrm{E}$ (the bad or evil) without a fail and motivates meaning of life in all the forms. In a nutshell, the simplified world-engagement is salient in Kung-fu films as one of the ideal patterns for the Chinese to see, to know and to interact with the world, which, simple as it may appear, is central to how Chinese people delineate and define basic categories of spiritual life.

\section{SELF-FULFILMENT FOREGROUNDED}

Another important characteristic of Chinese Kung-fu films is central to the necessity and merits of self-fulfillment of Kung-fu masters. This is not merely a plot design aimed to increase the theatrical appeal but also a paradigm faithfully reflecting how Chinese people define their own values by engaging themselves into the world. Not surprisingly, the way Chinese people approach to their values is different from that adopted by westerners who, more often than not, attach great importance to individually based achievements, say, winning the heart of the beloved, defeating a brutal foe in a fatal duel, saving the world after a single-handed fight against monsters or aliens. These typically Hollywood achievements mark an essential distinction compared with what Chinese Kung-fu films intend to elaborate on. Firstly, the Chinese counterparts are not exclusively talking about personal fulfillment of goals or dreams, but are incorporating Chinese-specific moral judgments into the narratives. Such moral preference is rooted in a Confucian society where people are taught to guide their thoughts and behavior in a clear binary way which in many cases is embodied into Junzi (morally good man) and Xiaoren (morally bad man). For example, almost all Kung-fu masters insist that the practice of Kung-fu is not meant to demonstrate strength or to impose dictatorship, but is intended to help the weak and restore the justice. Secondly, Chinese Kung-fu films tend to deal with the personal fulfillment of both the heroes and the antagonists. In other words, the antagonist may also have had an arduous experience before he or she achieves incredibly high levels of Kung-fu, but the martial feats he or she is practicing usually have evil implications, sometimes at the cost of moral degradation or physical alteration. A good example is Dongfang Bubai, a legendary Kung-fu giant who, in order to become the most competitive master, had to study a selfhurting martial feat and then ended up in becoming androgynous and whimsical. In a nutshell, along with a conceptually simplified way of character elaboration, both the protagonists and antagonists are depicted as driven by the desire of becoming the best, the key difference consisting in the moral acceptance of what they are doing and pursuing. In other words, self-fulfillment is occurring on both the good and evil sides, by foregrounding which, the Kung-fu films are meant to render a moral proposal as to self-fulfillment in which way is more desirable in a Confucian worldview.

More noticeably, the process of self-fulfillment is in itself highly dramatized for both of the two sides in terms of their path of world engagement. For the antagonists, as is mentioned 
above, the pursuit of exceptional power often comes with moral corruption and bodily damage, while for the protagonists, the very process teems with what is commonly regarded as intriguing and sensational in a reasonable, if not successful enough, film. Simply put, world-engagement for the antagonists is a trade-off, namely, the antagonists gain the highest possible level of achievement in the setting of Kung-fu world, say, martial feats, influences, dictatorship, hegemony, etc., but he or she has to sacrifice what is usually believed to be the most precious and meritorious in life, say, health and dignity. As for the protectionists, world-engagement is characterized of a movement from the periphery to the center of the world. In other worlds, protagonists are, in many cases, physically weak, socially marginalized, and emotionally oppressed in the very beginning. However, their growing interaction with the world brings about amazing experience (love affairs in many films, for example) as well as incredible opportunities to be able to practice and study a superb and extremely admirable (but often long lost in "Jiang Hu") martial art, thus enabling them to realize self-fulfillment. Reflecting on both scenarios, we may come up with an assumption that the "world" in Kung-fu films has a two-fold meaning: the first layer of the meaning is derived from the characters and plots, indicating a simplified and binarily oriented setting in which people are labeled and abstracted into flesh carriers of motivations, be they morally good or evil ones. The "world" is there to provide whatever is needed to ensure the selffulfillment of both protagonists and antagonists and this provision contributes to the narration as well. The second facet of the "world" connects the films to the reality. This means Kung-fu is the very and only social resource on which people are supposed to draw to realize their self-fulfillment. In this sense, Kung-fu is not merely a physical achievement or a personal practice, but publicly endorsed assets similar to gold, in relation to career, and associated with reputation. In other words, although the world-people relations are simplified, the world is not imagined (nor is "Jiang Hu"), but is there for real. The "world" is by no means different from the world perceived and experienced by any reader, except that it highlights Kungfu and dwarfs whatever that is irrelevant, thus foregrounding a Kongfu-based self-fulfillment. Therefore, such a pattern of self-fulfillment may be interpreted as a conceptual metonymy [7], where Kung-fu in the world depicted by novels and films is viewed as closely associated with what makes one successful and mighty in the world that is genuinely experienced, with a binary conception of moral issues going side by side with the acquisition of Kung-fu skills.

\section{RECONCILIATION OF CONTRADICTIONS}

Contradistinctions in almost all narrations are deemed as vitally important since readers and viewers by nature enjoy uncompromising people and events. That is probably why many works, especially those dubbed as modern or unconventional works are increasingly intrigued to equip narrations with multiple story lines and complicated casts of characters in order to achieve artistic or commercial success. More radically, works referred to as post-modern have gone even farther, reaching a point where contradictions become confusion, story lines are wiped off and characters die or suicide to signal the peak of monstrously mounting conflicts. Quite contrary to this trend, Chinese Kung-fu films well adhered to a predicable reconciliation of contradictions. This characteristic is worth mentioning for the following reasons. Firstly, Chinese philosophy is reputable for its admiration and pursuit of peace, especially peace in mind and in how things are done. In the case of the former, Tai-Chi, a typical Chinese Kung-fu feat serves as a pertinent example as it seeks inner harmony in line with the rules governing the universe. Such a structuralist viewpoint places special attachment to the inner mechanisms of people to reconsider what are troubling them by re-framing a conceptual space where worldly concerns of contradictions are flattened as "side-effects" of life arising from distractions from what are supposed to concentrate on or as "undigested lessons" of previous experiences leading to unscrupulous thoughts and behavior. For the latter case, Kungfu films have acted on the rationale that everything happens for a reason and that every problem calls for a solution. With this guideline, Kung-fu films seem to be more enthusiastic about resolving a problem than about implying how complicated these problems is. Yitian Sword and Tulong Blade, for example, are narrated as the origin of endless sinful slaughters in "Jiang Hu" as they are of supreme power and hence coveted by a wide array of Kung-fu masters. However, the story line is not strictly connected to the hatred and catastrophes initiated by these two weapons, but to the possibility and process as to how all the problems have been solved by the protagonist, who, in the end, settles all the disputes and brings harmony back to "Jiang Hu", an anticipated conclusion that rings the bell.

The second reason why the reconciliation of contradictions is important for Chinese Kung-fu films is that Chinese people have developed a somewhat collective thinking pattern in response to the fear of circularly unending chain of taking revenges [8]. More often than not, there is an incredibly wise man or woman in any Kung-fu film who is usually insignificant in terms of social status and will be appearing at some crucial point of time after long being ignored or unnoticed. Their debut, to the astonishment of all at present, is to provide a solution to almost all kinds of problems, a perspective that transcends habitual perception of many people and renders an insightful implication as to how things can be better seen and done. It means more than a solution; it is a philosophic instruction enlightening people on what can be more desired values and meaning of life. Compared with prevalent western modes of problem-solving where duels or confrontations are usually unavoidable, the Chinese mode does not consider a foe is necessarily and invariably a foe [9]. This may lead us to a preliminary conclusion that the world is negotiable in the eyes of Chinese people, thus the worldengagement is also a continuous negotiation with the world. Simply put, this world does poses obstacles and predicaments in whatever forms to make people feel detrimental, unfair, desperate and so on, but these experiences are recognized as integral part of life, even a must to presuppose one's future success. Kung-fu films simply profiles such a negotiation process, integrating self-fulfillment with world-negotiation, and making it a clear combination in line with the charactershaping and plot-designing.

It is important to stress that the world-negotiation does not only mean an approach to the reconciliation of contradictions, it is, if not exaggerated, a means to achieve fulfillment on the 
level of knowing better who "T" am, what the world is, and how "I" interact with it. If self-fulfillment we discussed in the previous chapter helps to shed a light on how a "self" has become the center of the focus of the "world" and what price one may pay to this end, world-negotiation here in this chapter is responsible to address what if one has been under the spotlight. Namely, how he or she may possibly reconsider what has happened and re-orientate himself/herself into a path leading to a most desired way of existence with knowing what the world really means. Such a pattern of life driven by a refreshed understanding of world-engagement is usually a comeback to what a normal track of life is like, say, staying aloof from the hustle and bustle, becoming interested in farming and gardening and so forth. As result, he or she disappeared in "Jiang Hu", which is the ultimate answer to all questions in the Kung-fu world.

\section{CONCLUSION}

We start from a brief analysis of how the world-people relations in Chinese Kung-fu films have been simplified and what this operation means so as to come up with a special world view characterized by "Jiang Hu", a vaguely defined living space of Kung-fu masters where a morally and aesthetically built binary judgment dominates. In such a world, self-fulfillment for both the protagonists and antagonists are important because they are pursuing a position in "Jiang Hu", thus realizing their respective engagement with the world. It is noticeable that this process is soaked up with the binary concern mentioned above, making dramatic plotting and theatrical appeal possible. However, self-fulfillment is not the final scenario to account for Kung-fu masters' interactions with the world; instead, they are confronted with the task of coping with contradictions and disputes. Almost with no exception, the masters prefer peace and tranquility, intrigued by a reclusive pattern of engaging with the world.
The seemingly simple conclusion has a deeply-seated origin that has yet to be illustrated to showcase how Kung-fu films are typically Chinese (but have been unsatisfactorily discussed). What we are intended to argue is that the worldengagement in Kung-fu films is a salient and crystallized version of how Chinese people aim to touch upon the essentials of world-people relations, to equip the world with clear-cut binary considerations, to achieve what the world is best possibly offering and to live a life the world is best possibly promising. In this way, Kung-fu is not about physical strength but about spiritual guidance.

\section{REFERENCES}

[1] Muqing. Xiong, Analytical Technique of Cognitive Poetics: A Case Study of The Eagle, Foreign Language Teaching and Research, 2012 (5), pp448-459.

[2] [Turner. M, The Literary Mind: The Origins of Language and Thought.Oxford: Oxford University Press, 1996.

[3] Freeman. M, The Fall of the Wall Between Literary Studies and Linguistics: Cognitive Poetics. In Gitte Kristiansen, Michel Achard, René Dirven, and Francisco Ruiz de Mendoza, eds. Applications of Cognitive Linguistics: Foundations and Fields of Application, pp403428. Berlin: Mouton de Gruyter, 2007.

[4] Langacker. R, Cognitive grammar, Oxford: OUP, 2008.

[5] Talmy. L, Toward a Cognitive Semantics, Vol II: Typology and Process in Concept Structuring.Cambridge/Massachusetts: The MIT Press, 2000.

[6] Dingfang. Shu, “Jingjie” and "Conceptualization”- Poetic Theory of Wang Guowei and Conceptual Theory in Cognitive Linguistics, Foreign Language Education, 2016 (7), pp1-5.

[7] Stockwell. P, Texture: A Cognitive Aesthetics of Reading. Edinburgh: Edinburgh University Press, 2009.

[8] Rong. Ma, The Essential Characteristics of Chinese Civilization, Academic Monthly, 2018(1), pp1-10.

[9] Bojun. Yang, Interpretations of Confucian Analects, Beijing: Zhonghua Publishing House, 1998.. 